\title{
Deep crust analysis beneath northern Vietnam by using receiver functions: Implications for SE Asia continental extrusion
}

\author{
Van-Duong Nguyen ${ }^{1,5}$, Bor-Shouh Huang ${ }^{2, *}$, Ya-chuan Lai ${ }^{2}$, Le Minh Nguyen ${ }^{1,5}$, Tu-Son Le ${ }^{1}$, \\ Van-Toan Dinh ${ }^{3}$, Kuo-Liang Wen ${ }^{4}$, and Hop-Phong Lai ${ }^{3}$ \\ ${ }^{I}$ Institute of Geophysics, Vietnam Academy of Science and Technology, Vietnam \\ ${ }^{2}$ Institute of Earth Sciences, Academia Sinica, Taipei City, Taiwan \\ ${ }^{3}$ Institute of Geological Sciences, Vietnam Academy of Science and Technology, Vietnam \\ ${ }^{4}$ Institute of Geophysics, National Central University, Taoyuan City, Taiwan \\ ${ }^{5}$ Graduate University of Science and Technology, Vietnam Academy of Science and Technology (VAST), Vietnam
}

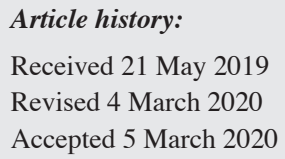

Article history:

Received 21 May 2019

Revised 4 March 2020

Accepted 5 March 2020

Keywords:

Crustal structure, Red River Shear Zone, Low-velocity zone, Northern

Vietnam, Receiver Function Method

\section{Citation:}

Nguyen, V.-D., B.-S. Huang, Y. Lai, L. M. Nguyen, T.-S. Le, V.-T. Dinh, K.-L. Wen, and H.-P. Lai, 2020: Deep crust analysis beneath northern Vietnam by using receiver functions: Implications for SE Asia continental extrusion. Terr. Atmos. Ocean. Sci., 31, 453-468, doi: 10.3319/ TAO.2020.03.05.01

\begin{abstract}
The shear-wave velocity structures of the crust and uppermost mantle of northern Vietnam were analyzed using the receiver function (RF) method at 25 broadband stations to investigate the regional crustal structure and its tectonic evolution. In this study, we presented a new crustal shear-wave velocity structure of northern Vietnam determined through RF analysis. Our results revealed significant variations in crustal thickness and deep crustal velocities across the study area. Along the Red River shear zone (RRSZ), the patterns of the crustal structure were distinct on both sides; they were simple and complex, respectively, in the blocks on northeast and southwest. A low-velocity zone (LVZ) was widely observed in the northwestern corner of the study area, and significant lateral variations in the thickness and strength of the crustal structure were observed from north to south. This LVZ was distributed as a thick and deep zone in the north and became thinner and shallower in the central region; the LVZ finally disappeared in the south. Two end members of the origin of the LVZ were proposed. The LVZ can be considered a weak crustal layer that escaped from the southeastern margin of the Tibetan Plateau, or it may have been formed from a paleo-subducted slab beneath it because of an onsite mantle heat source. The existence of this LVZ suggests that the movement of the RRSZ is possibly concentrated above the LVZ and that extension to the upper mantle is not necessary in the present stage. The above tectonic regime supports the possibility that the RRSZ is a strikeslip fault with a feature restricted in the crust.
\end{abstract}

\section{INTRODUCTION}

With an average elevation that exceeds $5000 \mathrm{~m}$, the Tibetan Plateau, the highest and largest plateau on Earth, is the direct consequence of an ongoing collision between the Indian and Eurasian plates that started at approximately $50 \mathrm{Ma}$ (Molnar and Tapponnier 1975). Deformation of the thickened continental crust requires lithosphere shorting and forms large-scale strike-slip faults surrounding the deformation (Royden 1996; Royden et al. 1997, 2008; Beaumont et al. 2001; Molnar and Dayem 2010). Far from the central Tibetan Plateau, northern Vietnam is mechanically connected

\footnotetext{
* Corresponding author

E-mail:hwbs@earth.sinica.edu.tw
}

to the Tibetan Plateau by the Red River shear zone (RRSZ) to the South China Sea (Fig. 1). The RRSZ extends for approximately $1000 \mathrm{~km}$ from the southeastern edge of the Tibetan Plateau through northern Vietnam. The RRSZ was formed in ancient times and is recognized as a boundary fault between the Sundaland Block and South China Block. It plays a crucial role in the tectonic regime in southeast Asia. The crustal motion of northern Vietnam is dominated by a clockwise rotation around the Himalayan syntaxis, according to geodetic and shear-wave splitting measurements (Shen et al. 2005; Bai et al. 2009; Duong et al. 2013; Trần et al. 2013; Le et al. 2014). Many geodynamical models have attempted to explain the deformation characteristics of the 
RRSZ in northern Vietnam and the adjacent regions (Tapponnier et al. 1982; Leloup et al. 1995; Chung et al. 1997; Lan et al. 2000; Roger et al. 2000; Beaumont et al. 2001; Searle 2006; Anczkiewicz et al. 2007; Royden et al. 2008) to explain the tectonic evolution of Asia. Studies have considered the RRSZ a large-scale strike-slip boundary fault that cuts the entire lithosphere with large geological offsets and high slip rates (Tapponnier et al. 1990, 2001). Studies have indicated that metamorphic rocks and granites along the RRSZ were produced because of shear heating along the fault that was caused by the collision (Leloup et al. 1995, 2001; Chung et al. 1997; Lan et al. 2000). However, the current role of the RRSZ has been debated as a pure crustalscale strike-slip fault, and it has been considered to respond to passive regional deformation with limited geological offsets and low slip rates (England and Houseman 1985, 1986). Those studies have indicated that igneous rocks observed on the surface are associated with the eastward migration of a weak lower crust beneath eastern Tibet; overall, a weak crust with rapid eastward flow within the deep crust was observed (Searle 2006; Royden et al. 2008). Two aspects are central to this debate, namely the rheological layering of the crust and the question of whether the upper crust is mechanically decoupled from the underlying lithosphere by a middle layer of high-temperature, partially molten rock that separates it from the lower crust (England and Houseman 1986).

Findings of geophysical studies have supported the rheological layering of the crust in central and southeast- ern Tibet. The ductile mid-crust usually is represented by a low-velocity zone (LVZ) with high crustal Poisson's ratios. Furthermore, these observations suggest the presence of a crustal flow channel and indicate that the crust and mantle are decoupled (Royden 1996; Beaumont et al. 2001). Receiver function (RF) and surface wave studies have presented evidence for a LVZ that began in central Tibet and reached the Yunnan region (Ozacar and Zandt 2004; Xu et al. 2007; Li et al. 2008; Chen et al. 2010; Tkalčić et al. 2011; Huang et al. 2013; Deng et al. 2019). Based on dense seismic array studies, the LVZ and crustal flow have been reported to extend into the eastern Himalayan syntaxis (Liu et al. 2014). Furthermore, Bai et al. (2010) reported that they detected a LVZ in the northwestern part of the Indochina Peninsula. Recently, Qiao et al. (2018) reported this LVZ extended to western side of the Dien Bien Phu fault based on results of ambient noise tomography. However, because of limited observations, the question of whether this LVZ extends to a broad area of northern Vietnam remains unanswered. Recent geophysical studies in northern Vietnam have reported that the crust is thickened and exhibits a high ratio of compressional wave velocity to shear-wave velocity $(\mathrm{Vp} / \mathrm{Vs}$ ratio) in its northwestern portion (Nguyen et al. 2013; Dinh et al. 2018); furthermore, a low shear-wave velocity anomaly was reported to extend from the mantle (Huang et al. 2013). However, thus far, no detailed regional seismic velocity model of northern Vietnam can be used for reference for additional discussion on this issue. A comprehensive velocity model that includes crustal and the
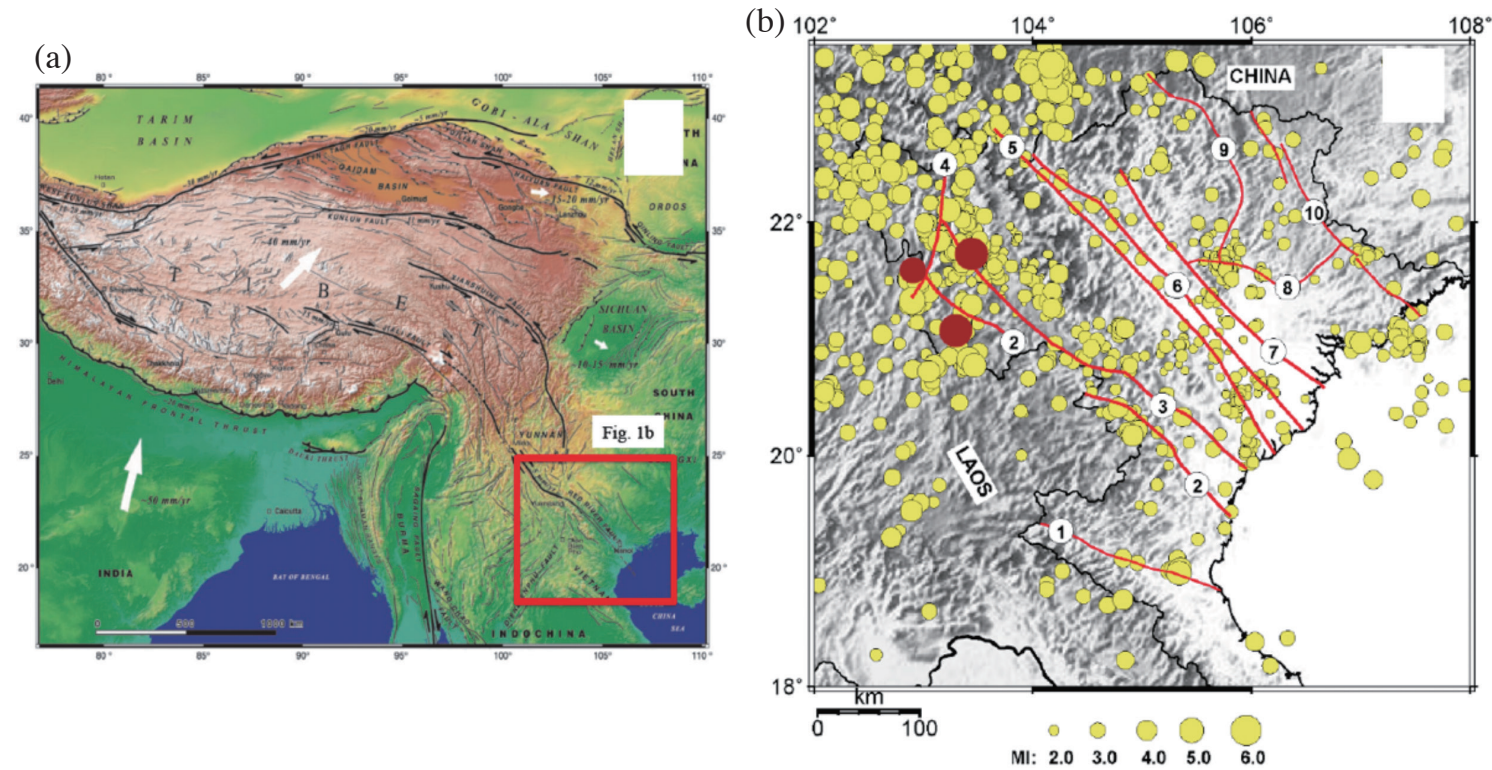

Fig. 1. (a) Map showing the topography and major active faults (black lines) in Tibet and adjacent regions (after Tapponnier et al. 2001). White arrows indicate direction motions of India, central Tibet, most northeastern Tibet, and Sichuan relative to Siberia. The box outlined in red is the location of (b). (b) Map of active faults in northern Vietnam. Thick and thin lines represent major and minor faults, respectively. The fault names are indicated by numbers (1: Ca River fault, 2: Ma River fault, 3: Son La fault, 4: Dien Bien Phu fault, 5: Red River fault, 6: Chay River fault, 7: Lo River fault, 8: Song Thuong fault, 9: Phu Luong fault, and 10: Cao Bang fault). Yellow symbols indicate regional seismicity reported by Nguyen and Le (2005) and brown circles indicate three hazard events of this area (Huang et al. 2009). 
uppermost mantle structures in northern Vietnam is necessary, and it will improve our understanding of geodynamic evolution processes and assessment of the role of the RRSZ.

In the present study, teleseismic earthquake data recorded by a 25 -station broadband seismic array over 7 years (from 2006 to 2012) in northern Vietnam were analyzed using the RF technique, which has been widely used previously for characterizing the crust in several regions (Langston 1979; Owens et al. 1984; Xu et al. 2007; Julià et al. 2009; Bai et al. 2010; Reading et al. 2012), to derive one-dimensional (1-D) shear-wave velocity profiles beneath each station through least-squares inversion of the RF waveform. We discussed the tectonic implications of our findings for crustal heterogeneity in this region and compared our results with the findings and predictions of previous studies.

\section{REGIONAL GEOLOGY AND CRUSTAL STRUCTURE}

\subsection{Geological Setting of the RRSZ}

Northern Vietnam is tectonically composed of the southeastern South China Block in the northeast and the northern Indochina Block in the southwest, which are separated by the NW-SE trending of the RRSZ. Furthermore, the geological structure of northern Vietnam is controlled by several major strike-slip fault systems, such as the Son La fault, Ma River fault, and Dien Bien Phu fault (Fig. 1). Along the RRSZ, high-grade gneiss and low-grade schist combine to form the Ailao Shan-Red River (ASRR) metamorphic belt comprising the Day Nui Con Voi in Vietnam and the Ailao Shan, Diancang Shan, and Xuelong Shan in Yunnan, China (Chung et al. 1997; Lan et al. 2000, 2001; Wang et al. 2000; Anczkiewicz et al. 2007; Trinh et al. 2012). The plate suture in northern Vietnam was considered the Ma River fault located in the southwest of the RRSZ (Fig. 1). This suture zone formed by ophiolite, island-arc, and orogenic and postorogenic igneous complexes, including a Permo-Triassic volcano-plutonic complex, indicates the existence of a paleo-subduction system (Lan et al. 2000; Hoa et al. 2008).

Several large igneous blocks adjacent to the RRSZ have been recognized in northern Vietnam. These rocks are extensively distributed and categorized by various groups of igneous rocks, which have been verified to evolve with a long and complex magmatism history (Lan et al. 2001; Hoa et al. 2008; Huang et al. 2013). According to metamorphic petrology, geological structure, and geochemistry dating studies, these rocks experienced a prolonged thermal history and are considered to form prior to the stage of shearing along the RRSZ (Anczkiewicz et al. 2007).

These structures are bounded by multiple active faults, such as the Dien Bien Phu fault, Red River fault, Ca River fault, Ma River fault, and Son La fault, in the northwestern part and the Yen Minh-Phu Luong fault in the northeastern part of northern Vietnam (Hoa et al. 2008) (Fig. 1). Northern Vietnam is considered a region with relatively low seismicity (Huang et al. 2009). In the study area, seismic activity was low along the RRSZ, and the same was observed in its northeastern region. However, in the western border of northern Vietnam, significant seismic activities and evidence were observed in the form of strong earthquakes and associated hazards (Fig. 1b). Destructive earthquakes have occurred in the northwestern part near Dien Bien in November 1935 and on 19 February 2001, as well as near Tuan Giao on 24 June 1983 (Huang et al. 2009) to be witness the current tectonic activity of the study area.

\subsection{Crustal Structure of Northern Vietnam}

In northern Vietnam, limited studies were previously conducted using wide-angle reflection or refraction data, and two crustal structure sections were constructed (Dinh et al. 2018). Because seismic signals were generated by relatively small shots, the crust-mantle reflection was not clearly visible in the data. A simple 1-D seismic model was processed from data deployed cross the RRSZ, which yielded an estimated crustal thickness of approximately $27 \mathrm{~km}$ in the margin of the Hanoi Basin (Dinh 2010; Dinh et al. 2018). In the past few decades, the 2-D crustal structure of northern Vietnam has been individually investigated using potential field data (Bui 1983; Cao 1985; Cao and Dinh 1999; Dang 2003; Dinh et al. 2018). The regional crustal densities and crustal interface boundaries were verified by comparison with reports of early geophysical surveys. A rough entire 3-D crustal model was reported by Dinh et al. (2018) by inverting Bouguer gravity anomalies. It revealed obvious lateral variations in the depth of the Moho discontinuity. The Moho depth increased from coastal regions to mountainous areas and increased more rapidly toward the northwest. However, in these studies, the crustal thickness was not adequately constrained by other geophysical information; the absolute Moho depth of the model was a trade-off for other crustal parameters. Using the $\mathrm{H}-\varkappa$ stacking algorithm of radial RFs (Zhu and Kanamori 2000), Nguyen et al. (2013) determined the crust thicknesses and Poission's ratios of northern Vietnam with more numerous constrains for Moho depths; however, data were collected only at locations beneath the 24 seismic stations analyzed in their study. The trends in the Moho depth determined by Nguyen et al. (2013) were similar to those estimated from gravity inversion by Dinh et al. (2018). Based on a Pn wave travel time tomography study, Huang et al. (2013) provided the first regional 2-D Moho and crustal velocity images beneath northern Vietnam. The model of Huang et al. (2013) showed significant lateral variation in the crustal and uppermost mantle velocities across the RRSZ; however, the model exhibited limited resolutions in depths. Regional seismic tomography studies have revealed large velocity variations in the upper mantle 
of southeast Asia (Lebedev and Nolet 2003; Li and van der Hilst 2010). Legendre et al. (2015) constructed the first regional structure of the lithosphere beneath northern Vietnam through surface wave tomography. Isotropic and azimuthally anisotropic phase-velocity maps of northern Vietnam at specific periods were reported. Magnetotelluric sounding has been used to explore the lithosphere in this region and revealed that a low-resistivity layer at a depth exceeding 15 $\mathrm{km}$ beneath the northwestern part of the study region and provided significant evidence for low resistivity in the midcrust and lower crust (Le et al. 2008, 2009). However, only limited sites in northern Vietnam have been surveyed.

\section{DEPLOYMENT AND SEISMIC OBSERVATIONS}

In an extensive collaboration between researchers of Academia Sinica, Taiwan, and the Vietnam Academy of Science and Technology, we deployed and operated 25 broadband seismic stations in northern Vietnam with an interval of approximately $100 \mathrm{~km}$ (Fig. 2a) from 2006 to 2012. The main aim of the network was to monitor earthquake activity in Vietnam and surrounding areas and provide information to enable imaging and interpretation of crust and mantle structures beneath northern Vietnam, including the geodynamic evolution of the RRSZ (Huang et al. 2009; Nguyen et al. 2013). The seismic network was equipped with Nanometrics Trillium 40 broadband sensors and Quanterra/Kinemetrics Q330 recorders with 24-bit analog-to-digital conversion. Seismometers were used to measure ground motion over a wide frequency range; a flat response was observed to velocities ranging from 0.025 to 50 $\mathrm{Hz}$. The ground motion signal was recorded continuously and digitized at a rate of 100 samples per second (SPS). All stations were equipped with a GPS timing system that was operated in the continuous mode to synchronize the internal clocks of stations.

During the network operation period, we selected more than 210 teleseismic events within the epicentral distance ranging from $30^{\circ}$ to $90^{\circ}$ with $\mathrm{M}_{\mathrm{w}} \geq 5.5$ to perform $\mathrm{RF}$ analysis (Fig. 2b). The number of recorded events included in the final analysis varied from 25 to 204 for a specific station, depending on the station operation length, background noise, and site condition (Table 1). Most of the selected events originated from the northwestern and southwestern Pacific Ocean, as well as along Indonesian islands. Azimuthal coverage was excellent on the east but relatively poor on the west (Fig. 2b).

\section{THE RF METHOD}

The RF method is an efficient technique for determining the crust and upper-mantle velocity structures beneath three-component broadband seismograph sites (Vinnik 1977; Langston 1979). The RF method used in this study consisted of two stages: (1) calculation of RF and (2) modeling to obtain shear-wave velocity structures of the crust.

RFs are calculated as follows. For teleseismic earthquakes, steeply incident $\mathrm{P}$-waves were recorded dominantly in the vertical component. When energy passed through velocity discontinuities in the upper mantle and crust beneath receiving stations, a part of that energy was converted into an S-wave that arrived later than the initial P-wave. The converted waves were recorded mainly on radial component and signal on transverse component through crustal shearwave anisotropy (Langston 1979; Ammon 1991; Reading et al. 2012). The radial component signal was deconvolved using the vertical component signal and the obtained waveform contained the effects of the near-receiver subsurface (Langston 1979; Owens et al. 1984; Ammon 1991). The resulting waveform was termed "radial RF" and is used in subsequent modeling for structure. Computation of RFs requires several processing steps including preprocessing of raw data, rotation into the ray coordinate system, deconvolution, and stacking. The preprocessing of raw data in this study consisted of resampling data to 20 SPS, and the window was between $40 \mathrm{~s}$ prior and $100 \mathrm{~s}$ after the $\mathrm{P}$ onset time. The data were demeaned and detrended, and a taper was applied before deconvolution. Two horizontal component traces were rotated to the directions of along and parapedicular to the great circular path and named radial and transverse components, respectively. A time domain iterative deconvolution technique proposed by Ligorría and Ammon (1999) was used to calculate RFs by using a Gaussian filter of 1.5, 2.5, and 5.0 in this study. When testing the above three Gaussian filters, large variations (e.g., Moho discontinuity) were prominently found on RFs by using a Gaussian width (1.5) filter. When two high-frequency (2.5 and 5.0) Gaussian filters were used, RFs showed thinner layering signals within the crust than those obtained using the Gaussian width (1.5) filter. At each station, RFs from all recorded events were manually inspected for its signal-tonoise ratio (SNR), and only results with a high SNR were used. In general, a dipping interface converted signals from the Ps phase (i.e., the P-to-S converted wave) to the transverse component RF across the full back azimuthal range. Studies have shown that a flat interface limited this conversion (Levin and Park 1997; Wirth and Long 2012; Ford et al. 2016). Examples from two stations of this study are shown in Fig. 3 with high SNR. RFs (both radial and transverse components) showed relatively simple variations with azimuth at station LSVB (Fig. 3a) but significant variations at station MLVB (Fig. 3b). It implied that the different characteristics of the crustal structure were observed beneath each station. To enhance the SNR of coherent signals, radial RF waveforms with similar ray parameters were usually stacked and suppressed spurious arrivals. The ray parameter $(r)$ is defined as the reciprocal of apparent velocity along the propagation ray inside the Earth, and the ray parameter 
(a)

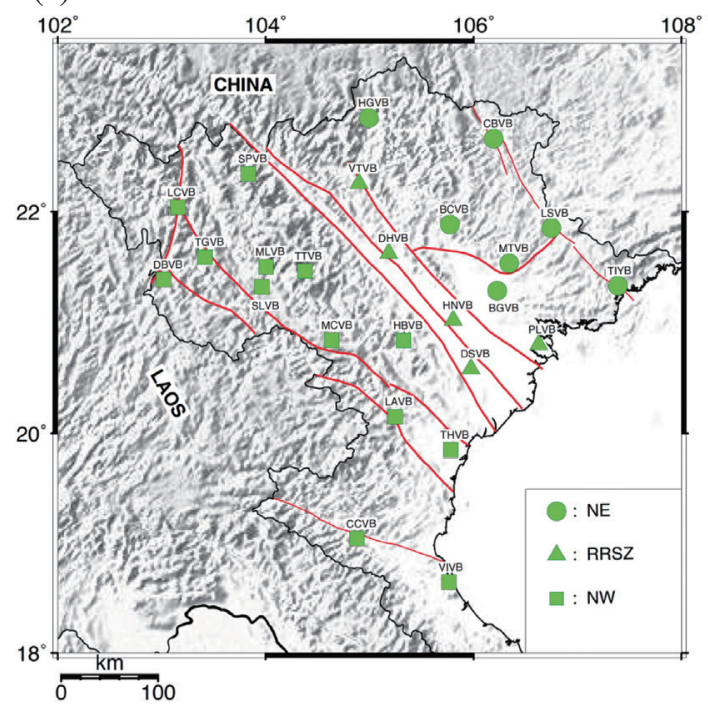

(b)

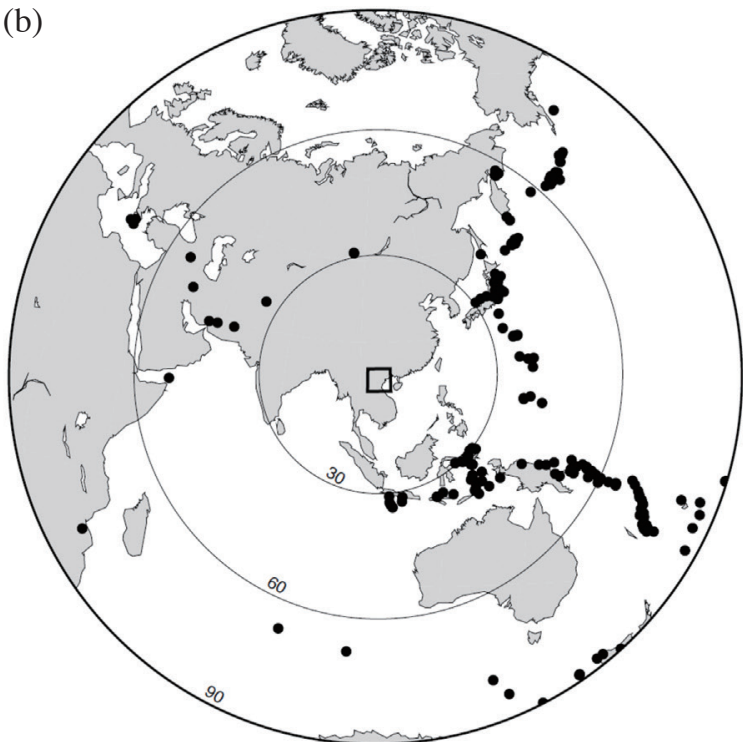

Fig. 2. (a). The distribution of seismic broadband stations in northern Vietnam. Four-letter station codes are written in black. Each green symbol indicates seismic station group from one of three geotectonic sectors (defined in this study as the NW, NE, and RRSZ sectors). (b). Azimuthal projections of epicenters of more than 220 earthquakes analyzed in this study (from January 2006 to December 2012), with projection centers in northern Vietnam (black rectangle). The epicentral distances range from $30^{\circ}$ to $90^{\circ}$ for earthquakes with a magnitude $\mathrm{M}_{\mathrm{w}}>5.5$.

Table 1. Values of crustal thickness and depth to CMT determined in this study for three sectors. Uncertainties on the mean values are $\pm 1 \sigma$.

\begin{tabular}{|c|c|c|c|c|c|c|c|}
\hline Sector & Station code & Lat $\left({ }^{\circ}\right)$ & Lon $\left({ }^{\circ}\right)$ & Elev (m) & No. $R$ & Crustal Thickness (km) & Depth to crust-mantle transition $(\mathrm{km})$ \\
\hline \multirow{7}{*}{ NE } & HGVB & 22.836 & 104.992 & 119 & 160 & $32.5 \pm 1.2$ & $32-34$ \\
\hline & CBVB & 22.652 & 106.194 & 223 & 96 & $32.5 \pm 1.1$ & $30-34$ \\
\hline & BCVB & 21.885 & 105.772 & 51 & 148 & $31.0 \pm 1.0$ & $30-32$ \\
\hline & LSVB & 21.853 & 106.749 & 285 & 159 & $30.0 \pm 1.2$ & $30-32$ \\
\hline & MTVB & 21.537 & 106.343 & 44 & 96 & $30.4 \pm 0.8$ & $30-32$ \\
\hline & BGVB & 21.29 & 106.228 & 14 & 142 & $29.4 \pm 1.0$ & $28-32$ \\
\hline & TIYB & 21.335 & 107.389 & 37 & 138 & $29.0 \pm 1.0$ & $30-32$ \\
\hline \multirow{5}{*}{ RRSZ } & VTVB & 22.253 & 104.899 & 71 & 106 & $32.5 \pm 1.7$ & $30-34$ \\
\hline & DHVB & 21.627 & 105.184 & 70 & 57 & $29.0 \pm 2.0$ & $30-34$ \\
\hline & HNVB & 21.025 & 105.804 & 39 & 25 & $28.5 \pm 2.8$ & $30-32$ \\
\hline & DSVB & 20.587 & 105.975 & 88 & 83 & $29.4 \pm 2.3$ & $28-34$ \\
\hline & PLVB & 20.805 & 106.628 & 6 & 186 & $29.9 \pm 1.1$ & $30-34$ \\
\hline \multirow{13}{*}{ NW } & SPVB & 22.338 & 103.835 & 1556 & 156 & $36.4 \pm 1.3$ & $36-42$ \\
\hline & LCVB & 22.039 & 103.155 & 205 & 81 & $31.4 \pm 1.4$ & $32-36$ \\
\hline & DBVB & 21.39 & 103.018 & 480 & 81 & $33.5 \pm 1.4$ & $26-34$ \\
\hline & TGVB & 21.592 & 103.418 & 574 & 204 & $31.5 \pm 1.3$ & $28-32$ \\
\hline & MLVB & 21.506 & 103.003 & 600 & 114 & $32.0 \pm 1.3$ & $30-34$ \\
\hline & SLVB & 21.325 & 103.965 & 607 & 139 & $32.0 \pm 1.0$ & $30-34$ \\
\hline & TTVB & 21.466 & 104.379 & 675 & 178 & $34.6 \pm 1.5$ & $32-36$ \\
\hline & MCVB & 20.844 & 104.635 & 826 & 158 & $33.0 \pm 0.9$ & $32-36$ \\
\hline & HBVB & 20.842 & 105.328 & 55 & 151 & $31.5 \pm 1.2$ & $32-36$ \\
\hline & LAVB & 20.153 & 105.248 & 54 & 129 & $29.5 \pm 0.9$ & $28-32$ \\
\hline & CCVB & 19.049 & 104.877 & 31 & 112 & $31.0 \pm 1.2$ & $28-32$ \\
\hline & VIVB & 18.65 & 105.763 & -6 & 181 & $28.5 \pm 1.3$ & $28-30$ \\
\hline & THVB & 19.851 & 105.782 & 1 & 177 & $26.5 \pm 1.2$ & $26-30$ \\
\hline
\end{tabular}



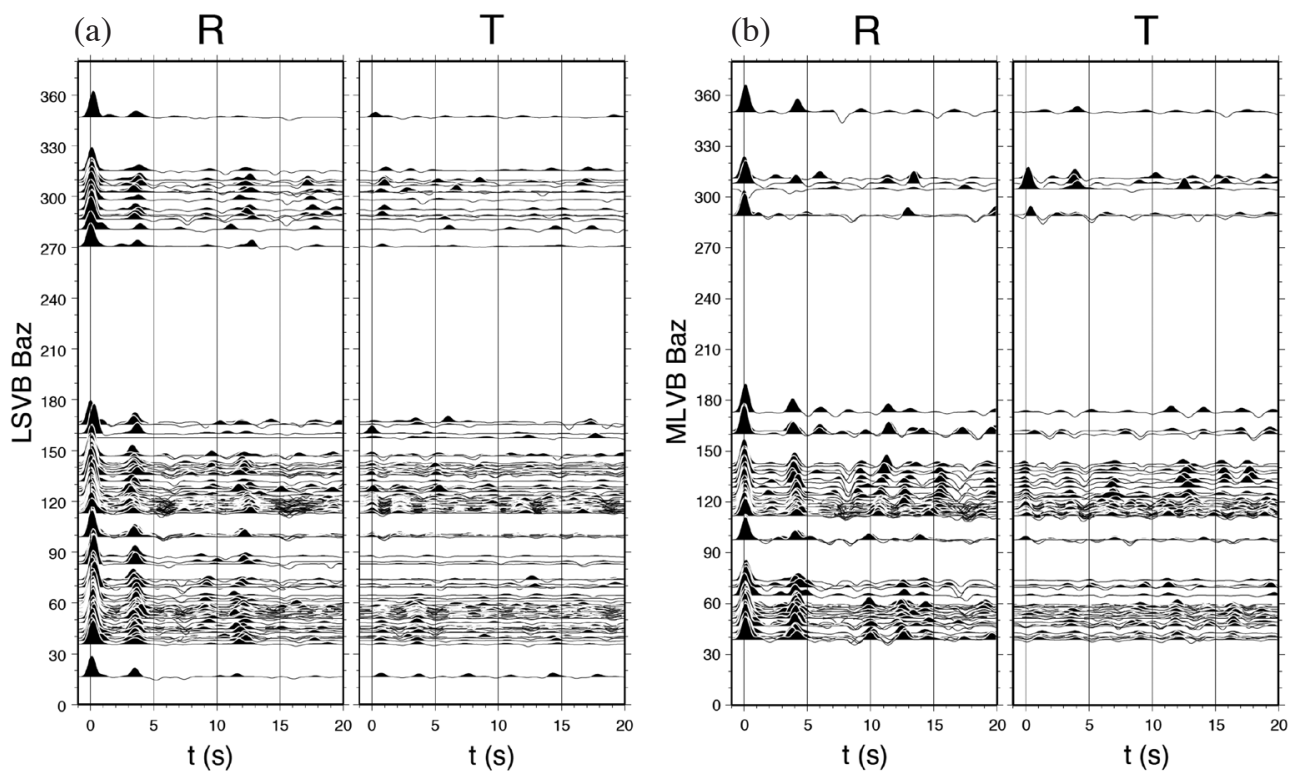

Fig. 3. Radial (R) and transverse (T) components of RFs as a function of back-azimuth for stations LSVB (a) and MLVB (b). Stations LSVB and MLVB were located at NE and NW sectors (Fig. 2a) defined in this study, respectively.

is always constant along the ray path (Shearer 1999). In the present study, radial RFs were stacked across all available azimuths for similar ray parameters. We grouped them into three categories of the ray parameters: $0.040 \leq r<0.055$; $0.055 \leq r<0.07$; and $0.070 \leq r \leq 0.085$. The average ray parameter of each group was used for the model inversion step. The examples of stacked radial RFs obtained from the data of earthquakes recorded at stations in northern Vietnam are shown as red waveforms in Fig. 4, and standard deviation bounds were calculated (dark gray waveforms in Fig. 4) for determining the constraints of inverted models. For the inversion step, in this study, the radial RFs were applied to a time window of between $-3 \mathrm{~s}$ and $25 \mathrm{~s}$.

In the second stage of the RF method, stacked RFs were inverted to yield a 1-D shear-wave model of the crust beneath the receiving station by using a time domain linearized least-squares inversion technique (Ammon et al. 1990; Herrmann and Ammon 2003). The aim was to obtain an average S-wave velocity model, from which a synthetic RF can be calculated, and the model was selected if it matched satisfactorily with the observed RF. The inversion results were evaluated using the correlation coefficients of the least-square fitting of simulated RFs to observational RFs that exceeded $90 \%$.

To demonstrate the inversion process, we tested four models. Those models have been considered four extreme cases of any real model. From these "true" models, we synthesized RF waveforms by using three ray parameters (Haskell 1962; Kennett 1983; Randall 1989; Herrmann and Ammon 2003). To generate initial velocity models for the inversion step, we added random perturbations to the reference model with prior information on crustal thickness and
$\mathrm{Vp} / \mathrm{Vs}$ ratio. All the 100 initial models produced solutions, but resulting models indicated that a wide range of $\mathrm{S}$-wave velocity models could fit synthetic "data" satisfactorily. We average all acceptable models to obtain the final model, which approached the "true" model (Fig. 5).

To invert the $\mathrm{S}$-wave velocity model of northern Vietnam by using the RF method, in this study, the initial model was reconstructed based on the results of previous studies (Berteussen 1977; Le 2008; Bai et al. 2010; Huang et al. 2013; Nguyen et al. 2013). After selection, this initial model was parameterized into the constant velocity layers of $2 \mathrm{~km}$ from the surface down to $70 \mathrm{~km}$. Furthermore, each starting model was randomly perturbed 100 times within a reasonable range of $\pm 0.6 \mathrm{~km} \mathrm{~s}^{-1}$ in the crust and $\pm 0.4 \mathrm{~km} \mathrm{~s}^{-1}$ in the uppermost mantle, which was based on the original model; the inversion was completed for each perturbed input model. In this study, the selected perturbed velocity ranges of crust and uppermost mantle were concluded based on our previous tests by using synthetic data of theoretical models. The purpose of the perturbation approach was to provide a set of new starting models, which would allow the exploration of a wide initial model space and reduce the dependence of solutions on the starting model (Hazarika et al. 2012). The final output model was developed by averaging all acceptable output models from each perturbed input model. The standard deviation bounds were computed to evaluate the complexity beneath each station.

\section{ANALYSIS RESULTS}

In the study, we divided northern Vietnam into three sectors by exploring the characteristics of tectonic elements 
and shear-wave velocity patterns: the northwest sector (NW), located on the left side of the Red River fault; the northeast sector (NE), located on the right side of the Red River fault; and RRSZ sector, along the RRSZ. The NE, NW, and RRSZ sectors had 7, 13, and 5 stations, respectively, as shown in Fig. 2a and Table 1. In this study, the analyzed RFs were the same as reported by Nguyen et al. (2013). On the basis of the quality of the original RFs, the stations were classified into three grades: A, B, and C and referred to Table 1 of Nguyen et al. (2013). Based on Nguyen et al. (2013)'s definition, the grade A stations display a clear arrival in the time window of $3.0-5.0 \mathrm{~s}$, which is considered as Ps, and at least one of the multiples close to the predicted arrival times. Grade B stations show clear Ps but not crustal multiples. Grade C stations show only Ps phase of RFs observed but other crustal phases cannot be identified. Based on Table 1 of Nguyen et al. (2013), 7 stations were defined as grade A, 12 stations as grade $\mathrm{B}$, and 5 stations as grade $\mathrm{C}$. One new station (MLVB) analyzed in this study was graded as A based on the definition of Nguyen et al. (2013).

The characteristics of RFs, such as the amplitude of the directed phase and the amplitude and timing of the conversion and reverberation phases, may provide information regarding the nature of the tectonic structure beneath the station (Owens and Crosson 1988; Cassidy 1992; Julià 2007; Reading et al. 2012). Usually, the Moho sharpness is evident from the amplitude of Ps converted phase and reverberation phases in the RF. Crustal discontinuities become evident as converted phases before the Moho arrival. The small amplitude of the directed $\mathrm{P}$ phase in RFs may have been caused by the low velocity near the surface beneath these stations (Julià 2007).

\subsection{Radial RF Averages}

RFs presented simple and similar waveforms for stations in the NE and RRSZ sectors (Fig. 6). The RF characteristics indicated clear and coherent Moho conversion (Ps phase) and reverberation phases (PpPs and PsPs + PpSs). The time delay of the Moho conversion phase was approximately $3.3-4.0 \mathrm{~s}$ for the NE sector and $3.3-3.8 \mathrm{~s}$ for the RRSZ sector. The crustal converted phases before the Moho arrival were small, except for stations HGVB (NE) and DSVB (RRSZ), which suggested that crustal structures beneath these sectors were relatively simple (Fig. 6). RFs from stations in the NW sector are notable for their high variation in the amplitude of the signal and lack of clear reverberation phases (e.g., PsPs + PpSs). The Moho conversion phase exhibited a time delay of $3.0-4.8 \mathrm{~s}$. The crustal converted phases are shown as significant in stations in the NW sector (TGVB, LCVB, SPVB, and MCVB). The amplitude of the directed $\mathrm{P}$ phase of stations TTVB, MLVB, SLVB, and MCVB was smaller than that of others. It was affected strongly by the low velocity in the upper crust beneath these stations (Julià 2007). The strong negative amplitude at stations HGVB (NE), TGVB, LCVB, and SPVB (NW) probably represented a $\mathrm{P}$-to-S conversion from a middle-lower crust LVZ (Fig. 6). Based on characteristics of relevant RFs, new information on the crustal structure was expected to improve our understanding of the tectonic development of northern Vietnam.

\subsection{1-D S-Wave Velocity Models}

The stacked radial RFs (Fig. 6) with three overlapping Gaussian widths were inverted to obtain an average shear-wave velocity model for each station by using the linearized inversion method (Ammon et al. 1990). Examples of inverting the stacked radial RFs are shown in Fig. 7. In general, observed and synthetic RFs that were synthesized from the inverted $\mathrm{S}$-wave velocity model exhibited an excellent match, and the uncertainty was less than 10\%; hence, the models were reliable. All inverted shear-wave velocity models divided by the three sectors of northern Vietnam are shown in Fig. 8. A crust-mantle transition (CMT) is marked in each inverted S-wave velocity profile (Fig. 8). The CMT is a class of geologic features that are perhaps most suitable for seismic investigation, namely major boundaries in elastic properties. Elastic boundaries are the source of specific seismic waves (reflections, refractions, and diffractions) that affect seismograms; hence, they are the central data in any seismic analysis (Ligorría 2000). In this study, the CMT was considered as a tectonic signature and combined with the characteristics of the shear-wave velocity profile of sectors for further evaluation.

NW sector: The S-wave velocity models revealed significant variations in this sector (Fig. 8a). An intra-crustal LVZ was evident beneath the stations located in the northern and central parts of this sector; the thickness of this zone varied in the range of $4-16 \mathrm{~km}$ in the middle and lower crust at the depths of approximately $16-20$ to $32-34 \mathrm{~km}$. The upper crust in the central part was also characterized by a low-velocity layer from the surface down to $16 \mathrm{~km}$. The LVZ in the middle and lower crust was unclear at stations MCVB and TTVB; however, the inverted results showed that the crustal $\mathrm{S}$-wave velocity of these stations remained low. The LVZ present beneath this sector appeared to be terminated at MCVB. The LVZ was not found beneath the stations in the southern part of this sector (LAVB, CCVB, VIVB, and THVB).

The $\mathrm{S}$-wave profiles showed that the crust of this region was highly complex. The thickness of the CMT zone varied in the range of $4-8 \mathrm{~km}$ at depths in the range of $26-42 \mathrm{~km}$ in the northern part and was approximately $4 \mathrm{~km}$ at depths in the range of $30-36 \mathrm{~km}$ in the central part (Fig. 8a and Table 1). The CMT zone of southern stations was pronounced at a depth of approximately $26-32 \mathrm{~km}$, and the thickness of this zone was approximately $2-4 \mathrm{~km}$ (Fig. 8a and Table 1). 
The shear-wave velocity models beneath the southern part were simpler than those beneath the northern part. The depth of the CMT zone in the NW sector was generally consistent with the estimates of crustal thickness reported previously (Bai et al. 2010; Nguyen et al. 2013).

$N E$ sector: The $\mathrm{S}$-wave velocity profiles showed three prominent layers at most stations in this sector (Fig. 8b), namely the upper layer (or upper crust) that extended to a depth of $8-14 \mathrm{~km}$, which became increasingly complex from region to region; the middle layer in the region between 8 and $14 \mathrm{~km}$ and 18 and $24 \mathrm{~km}$; and the lower layer that extends to the CMT zone. The S-wave velocities in the lower layer gradually increased. A low-velocity layer was evident beneath the stations HGVB and CBVB but not obvious beneath the other stations in this sector. The CMT zone was clear and pronounced beneath this sector. The depths of the CMT zone in this sector were approximately in the range of $28-34 \mathrm{~km}$ with a thickness of approximately $2-4 \mathrm{~km}$ (Fig. 8b). These results are consistent with the H- $x$ estimation reported by Nguyen et al. (2013) and Deep Seismic Sounding (DSS) results (Dinh et al. 2018).

RRSZ sector: The RRSZ structure was sampled at the stations VTVB, DHVB, HNVB, DSVB, and PLVB. Low shear-wave velocity in the upper crust was found beneath stations DHVN, HNVN, and DSVB at a depth of approximately $6-10 \mathrm{~km}$. The depth of the CMT zone was approximately $28-32 \mathrm{~km}$, with a thickness of $2-6 \mathrm{~km}$, which was consistent with the estimates of crustal thickness obtained using the $\mathrm{H}-x$ estimation (Bai et al. 2010; Nguyen et al. 2013). The CMT zone has a gradient or low-velocity contrast. The upper part of the S-wave models, which extended to approximately $14 \mathrm{~km}$, showed higher complexity than the middle and lower crust (Fig. 8b). Overall, compared with stations of sectors NW and NE, the S-wave velocities of this sector were higher (Fig. 8); the difference may be in response to the depth extension of high-grade gneiss and lowgrade schist of the ASRR metamorphic belt from surface.

\section{DISCUSSION}

Because limited information is available on the crust beneath northern Vietnam, in this study, we referred and fixed the crustal thickness, $\mathrm{Vp} / \mathrm{Vs}$ ratio, and density at each station based on the estimates by Nguyen et al. (2013) and those by Berteussen (1977) to reduce the dependence on the initial model. The S-wave velocity models were obtained by
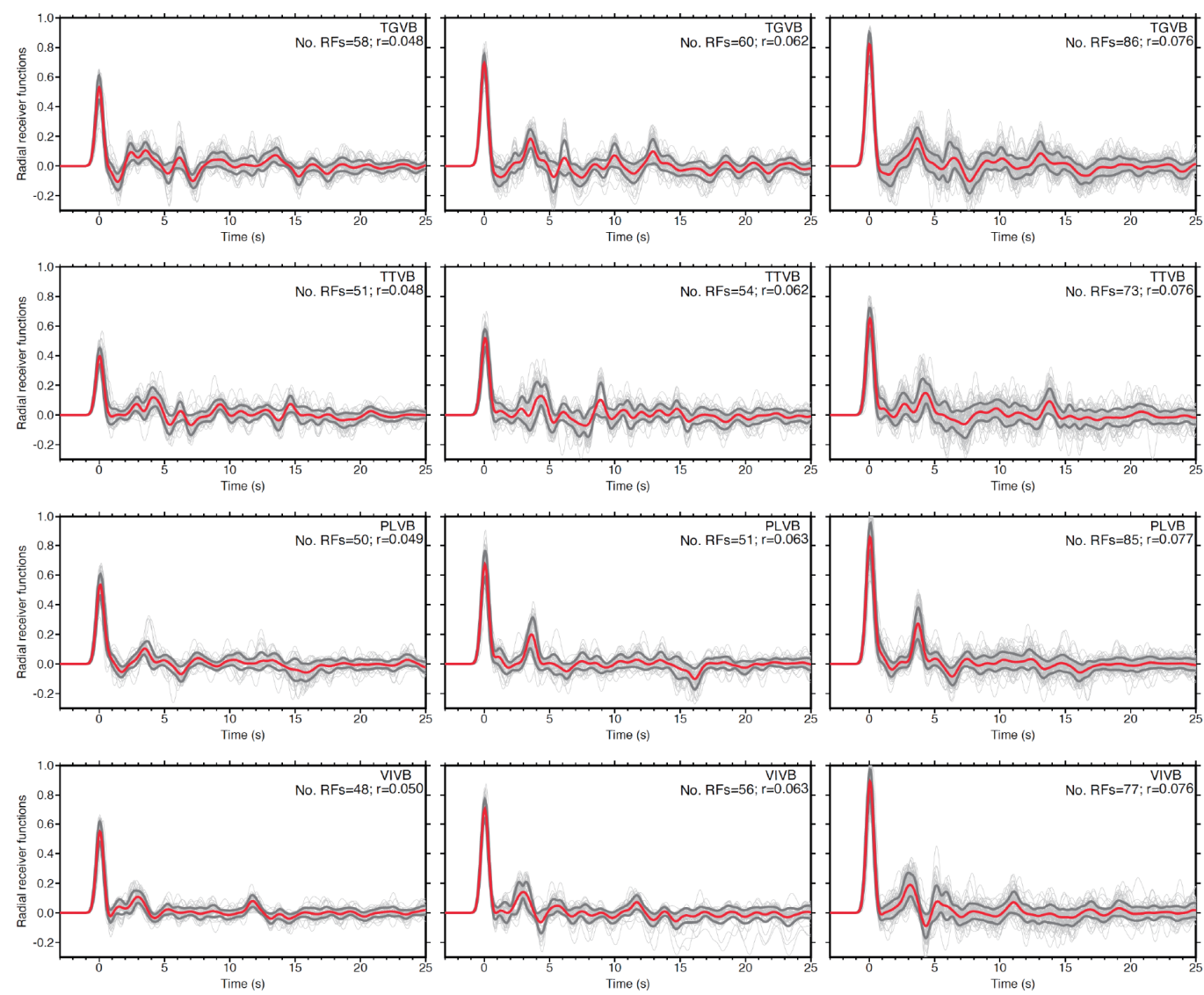

Fig. 4. Examples of average RFs for stations TGVB, TTVB, PLVB, and VIVB calculated using a Gaussian filter width $a=2.5$ for three categories of ray parameters. Thin lines in gray are individual radial RFs. Average RFs for each group of ray parameters are shown in red along with $2 \sigma$ bounds (two thick black lines). Numbers of radial RFs (No. RFs) and ray parameter $(r)$ of averaged RF are shown within each plot. 

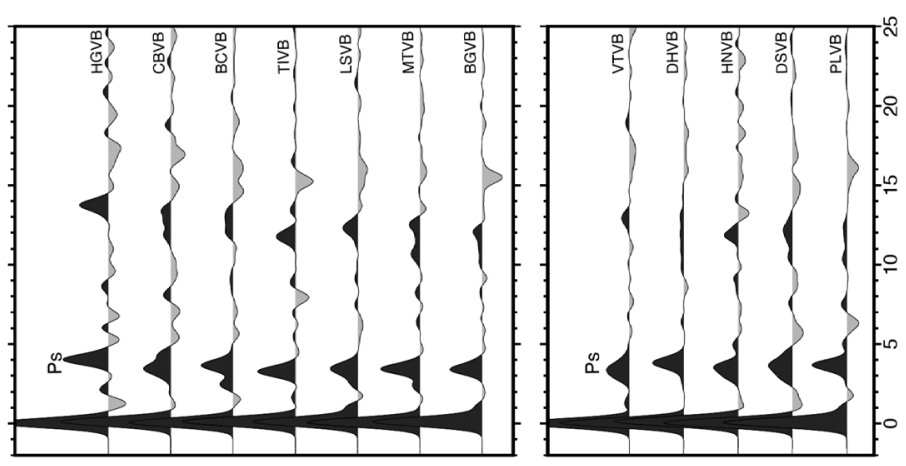

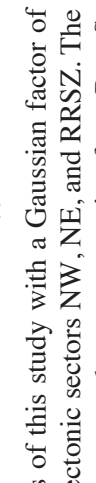

이오 zsy్d

范 :
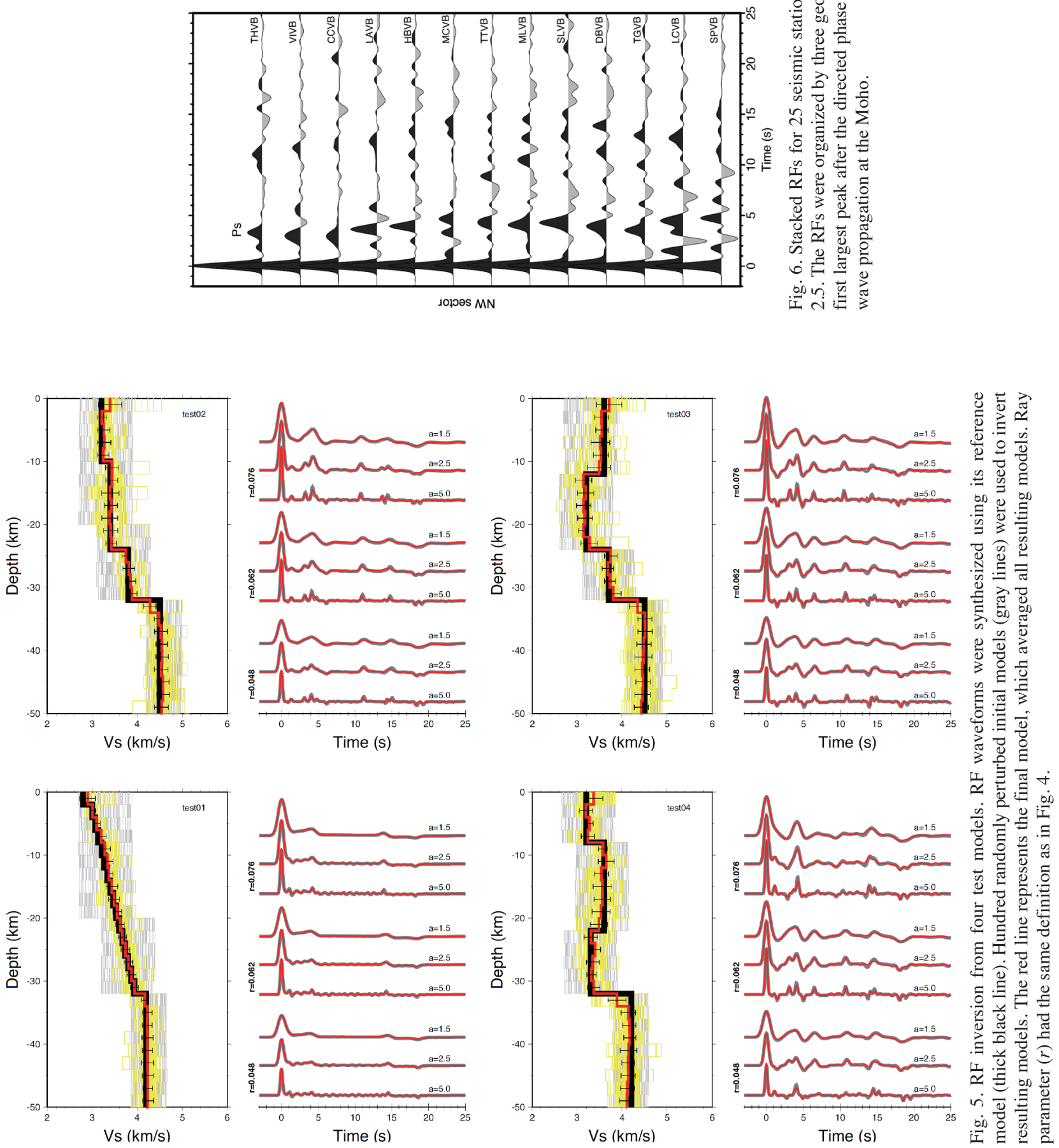

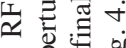

它

若

वृ:

政

멍

亏.छ

की

$\Xi$ 还

$\simeq$ 이

讧 छ 巳 

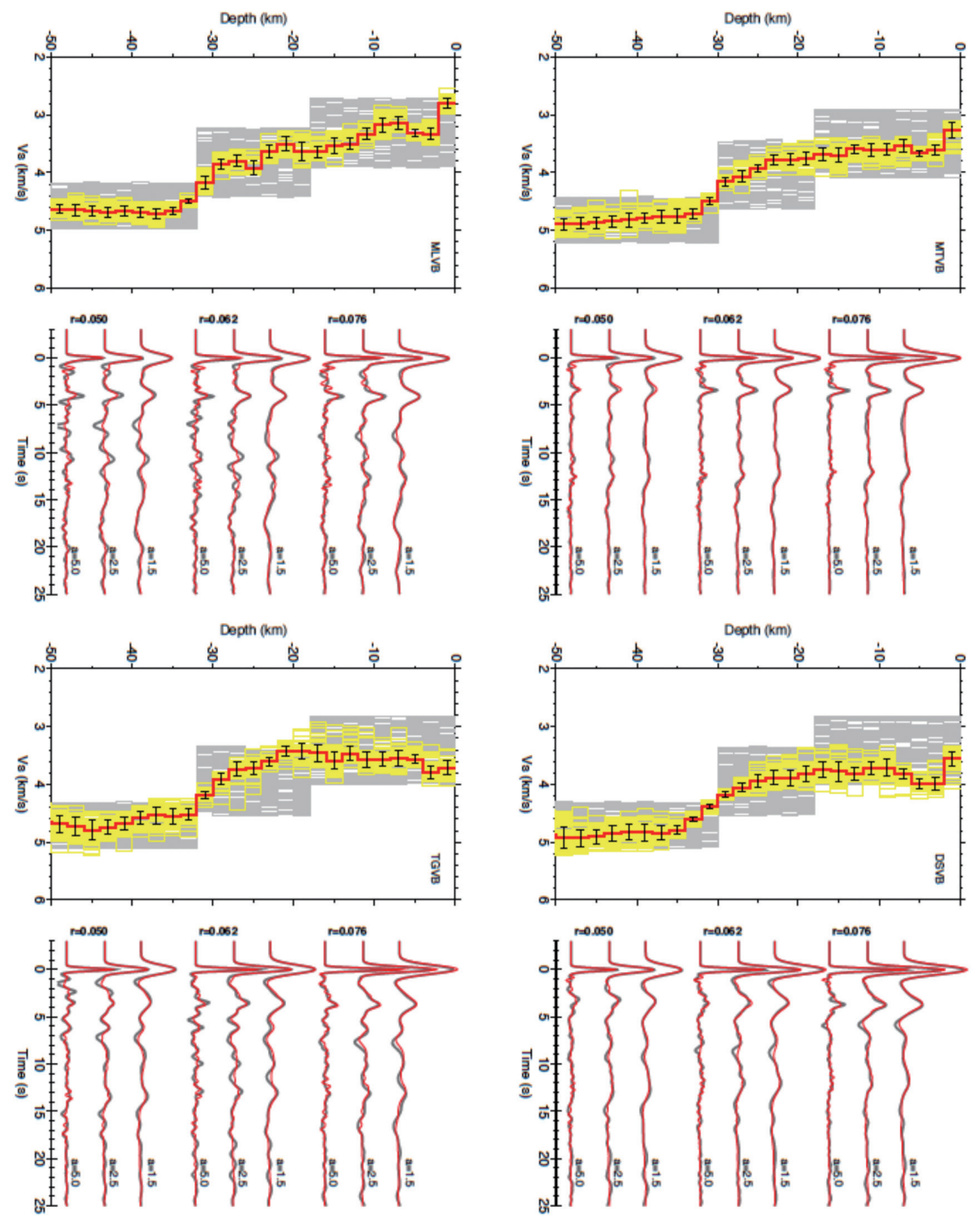

Fig. 7. Examples of RF inversion results for stations MTVB, DSVB, MLVB, and TGVB. The observed (gray) and simulated RFs are shown in the right panel for each station. The shear-wave velocity profiles are shown in the left panel. The thin lines in gray are the 100 initial models used in the waveform inversion. The acceptable solution models obtained after 200 iterations are shown in yellow. The averaged models with $2 \sigma$-confidence bound (black lines) for each station are shown in red. 
(a)

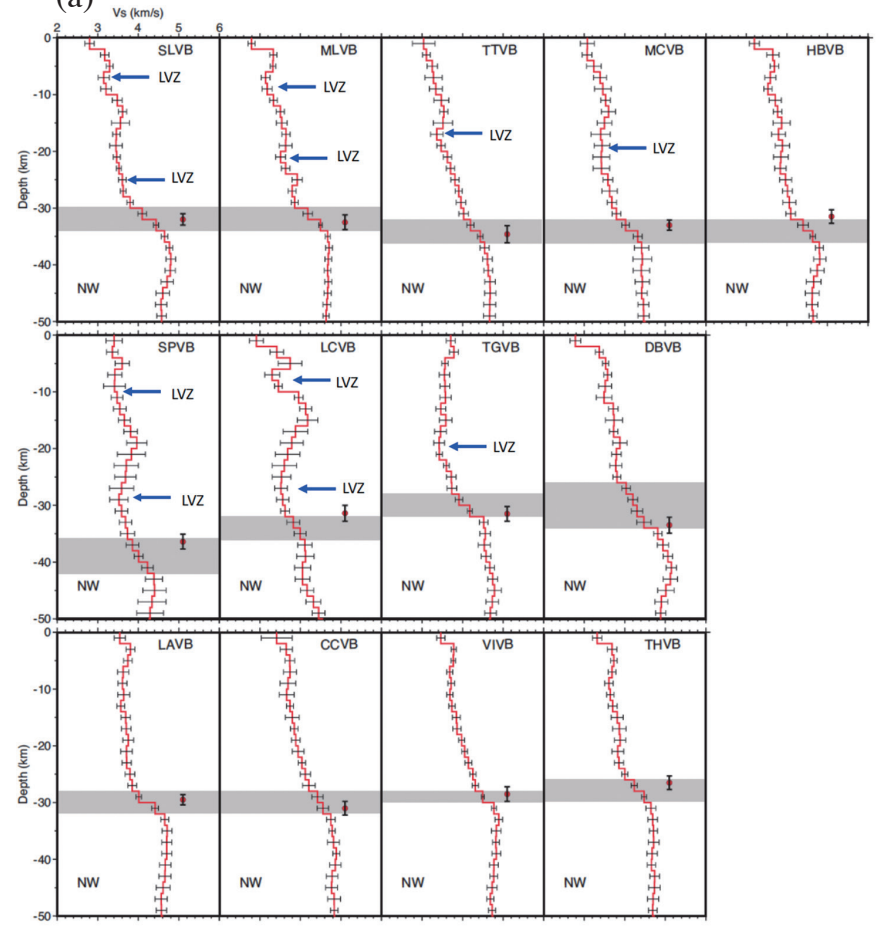

(b)

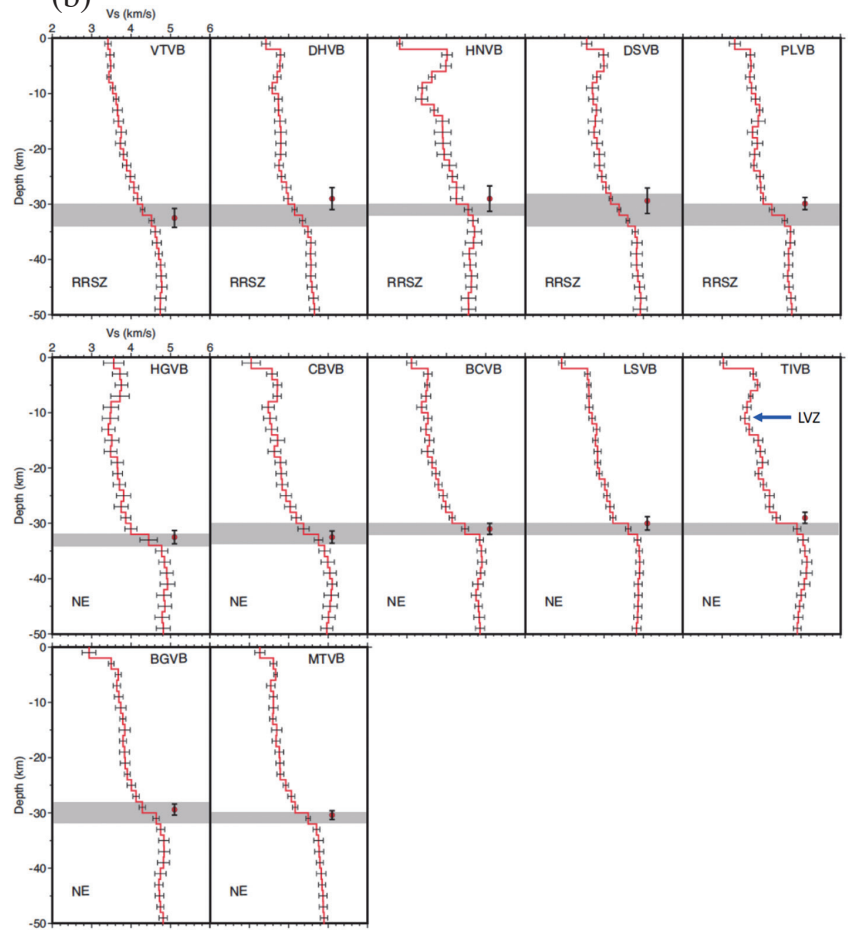

Fig. 8. Shear-wave velocity profiles arranged by geotectonic sectors; (a) for NW sector and (b) for RRSZ and NE sectors. The models are shown as thick red lines along with $2 \sigma$ standard deviations. The gray bars indicate the CMT boundary. The blue arrows with label LVZ indicate the observed low velocity zone beneath some stations in northern Vietnam. The red dot with standard deviation bar on each seismic profile is the crustal thickness estimated using the $\mathrm{H}-\boldsymbol{x}$ stacking method (Table 1, updated from Nguyen et al. 2013).

inverting the stacked RFs by using the independent initial model beneath each station, and results revealed that a wide range of seismic velocities could fit the observations. The independent inversion models typically provided a satisfactory match between synthetic and observed RFs; however, the low variation among models provided more confidence that average models shown in Figs. 5 and 7 are robust. The $2 \sigma$ confidence bounds were computed using standard deviations for 100 independent inversion models, and it conveys the confidence range of variation of velocity among the models. The confidence bounds for all the stations showed that uncertainties in the crust and uppermost mantle were larger beneath stations in complex regions (i.e., NW sector) and smaller in stable regions (i.e., NE sector) (Fig. 8).

The crustal structure results described in this study were actually the first $\mathrm{S}$-wave velocity models that have been reported for the entire region of northern Vietnam by using dense seismic array observations. Legendre et al. (2015) reported a structure of the lithosphere beneath northern Vietnam based on teleseismic surface wave dispersion analysis of Rayleigh-wave phase velocity. Legendre et al. (2015) concluded that lateral variation was observed in the lithosphere model of northern Vietnam; high velocities were observed beneath the South China Block, and low velocities were observed beneath the areas between the Red River Fault and the Song Da Fault. In general, the inverted 3-D model was consistent with that of the RFs study; however, resolutions in the crust are limited. Bai et al. (2010) used RF data to estimate the crustal and uppermost structure beneath four stations, namely SPVB, DBVB, PLVB, and VIVB, in northern Vietnam. Nguyen et al. (2013) used RF data to estimate the crustal thickness and $\mathrm{Vp} / \mathrm{Vs}$ ratio beneath 24 stations in northern Vietnam. In this study, the S-wave profiles beneath northern Vietnam were estimated using dense seismic array observations (Fig. 2a). Some discrepancies emerged among our results and those reported by Bai et al. (2010); for example, the S-wave velocity in the uppermost mantle beneath station SPVB from this study is relatively smaller than that reported by Bai et al. (2010). This problem was also encountered at PLVB. This discrepancy is possibly due to the use of different datasets. More observations have been analyzed for RF inversion in this study than that conducted by Bai et al. (2010). However, the consistency of the S-wave velocity profiles of Bai et al. (2010) and this study indicated the S-wave profile complexity and the LVZ within the crust at station SPVB. This is also correlated with the high $\mathrm{Vp} / \mathrm{Vs}$ ratio in the NW sector (Bai et al. 2010; Nguyen et al. 2013). The LVZ may be related to the existence of a conductive zone from a depth of $10-30 \mathrm{~km}$ that was found beneath NW sectors (Le et al. 2008, 2009). In general, the depths of the CMT zone in this study were consistent with the estimated crustal thicknesses reported in previous 
studies (Bai et al. 2010; Huang et al. 2013; Nguyen et al. 2013; Dinh et al. 2018).

The results of this study (Fig. 8) showed that a widespread LVZ was observed in the northwestern part of northern Vietnam with significant lateral variations in its thickness and strength from north to south. Evidence for a LVZ in the middle and lower crust was observed beneath the northern part of the NW sector (namely the stations SPVB, LCVB, and TGVB) but that evidence was weaker in the central sector (namely the stations SLVB, MLVB, TTVB, and MCVB) and disappears in the southern sector (Fig. 8a). On a large scale, the presence of a LVZ in this sector is probably associated with a LVZ beneath central and southeastern Tibet (Ozacar and Zandt 2004; Xu et al. 2007; Bai et al. 2009; Li and van der Hilst 2010; Qiao et al. 2018; Deng et al. 2019). This evidence is also consistent with findings reported by Le et al. $(2008,2009)$. The observed LVZ was suggested to result from the rapid eastward flow of the deep crust from the central Tibetan Plateau (Searle 2006; Royden et al. 2008). According to a different viewpoint, the origin of this LVZ was considered to be caused by an old subduction zone in this area (Huang et al. 2002). The subduction processes provided upwelling of a heat source from the melt slab to the uppermost mantle and imparted ductile material to the crust and caused partial melting of the crust (Leloup et al. 1995, 2001; Hoa et al. 2008; Lei et al. 2009; Balykin et al. 2010).

In this study, we identified the spatial distribution of the LVZ beneath some seismic stations of northern Vietnam. A LVZ is considered as a material weak zone. Because of tectonic pushing, major horizontal crustal movements occurred above this LVZ and the fault slip is limited on the crust. The existence of the observed LVZ in northern Vietnam appeared to suggest that the movement of the RRSZ was possibly concentrated above the LVZ and did not necessarily extend to the upper mantle. This tectonic regime indicates that the RRSZ is a pure crustal-scale strike-slip fault in the present stage, which responds passively to regional deformation (England and Houseman 1985, 1986).

The origin of a LVZ can be explained as the formation of hot and soft material because of residual heat escaping from the eastern Himalayan syntaxis or an onsite mantle heat source because a subducted slab lies beneath it. This tectonic feature implies the existence of low seismicity along the RRSZ and its northeastern region (Fig. 1b). Other implication of the NW sector is the interaction of three adjacent blocks, the South China Block, Sundaland Block, and Baoshan sub-block, which indicated that the NW sector should be considered a transition boundary zone (Shen et al. 2005; Duong et al. 2013). It responded to the tectonically active NW sector. Earthquakes have been reported to occur on several boundary faults and were not concentrated only on the RRSZ (Fig. 1b).

Inside northern Vietnam, we consistently found evi- dence of S-wave velocity structures that might be related to different tectonic processes reported in previous geological observations and its discussions. All five stations along the RRSZ (RRSZ sector) exhibited similar CMT boundaries with an extremely low contrast velocity (Fig. 8b), which may be due to the uplift and exhumation of the mantle (Anczkiewicz et al. 2007). The hot mantle may reduce the velocity of uppermost mantle and the same as the low velocity contact across Moho. Three stations in this sector, namely DHVB, HNVB, and DSVB, exhibited an upper crust (underneath the stations) that was more pronounced and complex than that beneath the HBVB in the NW sector. The implications of this finding are associated with the rifting process in the middle Paleogene (Le 1985). The LVZ in this layer suggested the effect of geothermal activities caused by rifting (Liong Tin and Litvinenko 1986; Dinh et al. 2018). We also found limited evidence regarding variations in the crustal structure in the NE sector. The stations in the northern part of this sector (stations HGVB and CBVB) were more complex than those in the southern part. The high velocity layer in the upper crust (approximately $8 \mathrm{~km}$ ) was superincumbent on the LVZ and may be related to the cooling process of the Song Chay dome in the Eocene-Oligocene transition or to two successive exhumation phases because of the two orthogonal compressions that have effected to northern Vietnam (Roger et al. 2000). Similar to the S-wave velocity structure, the crustal thickness for the other stations in the NE sector (namely stations BGVB, MTVB, LSVB, and $\mathrm{BCVB}$ ) suggested small changes over tectonic history in the process that formed the crust.

\section{CONCLUSIONS}

In this study, we presented a new crustal shear-wave velocity structure of northern Vietnam obtained through RF analysis. The following conclusions can be drawn from our study:

(1) Our results revealed a significant variation in the NW sector, and the crustal thickness increased northwestward; it ranged between 28 and $40 \mathrm{~km}$. However, the crustal thickness in the NE and RRSZ sectors was not complex, approximately $31 \mathrm{~km}$ in the RRSZ sector and approximately $32 \mathrm{~km}$ in the NE sector, which confirmed our results obtained using the $\mathrm{H}-x$ method (Nguyen et al. 2013).

(2) The primary new observations of shear-wave velocity showed that considerable variability existed among tectonic units in northern Vietnam. Along the RRSZ, the shear-wave velocity gradually increased with depth, and the CMT zone exhibited a gradient or low contrast. It suggested that the mantle was uplifted and exhumed along this shear zone. The LVZ in the upper crust of this zone may be related to geothermal heat flows caused by rifting. The two sides of the RRSZ exhibited distinct crustal 
structure patterns. The north side (NE sector) had a simple pattern of the shear-wave structure, which implied small changes in the long tectonic history in the process that formed the crust. By contrast, the south side (NW sector) exhibited considerable variation in the crustal shear-wave velocity. The crustal structure patterns in the north of this sector were the most complex. We found that the shear-wave velocity in this region was the lowest compared with that in other regions in northern Vietnam. However, the crustal structure patterns in the south of this sector were simpler. These findings suggested that tectonic processes in the northern sector were more active, whereas those in the south were more stable.

(3) The LVZ was widely observed in the northwestern part of northern Vietnam, but significant lateral variations were observed in the depth and strength of the LVZ. It was broader and deeper in the north but thinner and shallower in the central area; moreover, it disappeared in the south. We inferred the possible existence of the crustal partial melt in the crust. Our interpretation was supported by high $\mathrm{Vp} / \mathrm{Vs}$ ratios, observations of low crustal resistivity, and high temperatures in the upper mantle and crust (Le et al. 2008, 2009; Nguyen et al. 2013; Sun et al. 2013).

(4) The existence of the LVZ further supported the possibility of a crustal-scale RRSZ. The origin of the LVZ was due to the escape of residual heat from the eastern Himalayan syntaxis or was a result of the onsite mantle heat source from subducted slab beneath it.

Acknowledgements We appreciate the staff of the Vietnam Academy of Science and Technology and Academia Sinica for collecting the data used in this study. Dr. R. B. Herrmann provided insightful comments on the inversion technique. We also thank Dr. H. H. Huang, Prof. M. W. Yeh, and T. Y. Lee for insightful comments and valuable discussions. This study was funded by the Ministry of Science and Technology (MOST) of Vietnam, grant NDT.18. TW/16, Vietnam Academy of Science and Technology, grant VAST.HTQT.NHATBAN.01/2015-2017 and grant VAST06.02/20-21, and by the Ministry of Science and Technology, Taiwan, grant MOST 105-2923-M-006-006MY3 and grant MOST 107-2119-M-001-048.

\section{REFERENCES}

Ammon, C. J., 1991: The isolation of receiver effects from teleseismic $P$ waveforms. Bull. Seismol. Soc. Am., 81, 2504-2510.

Ammon, C. J., G. E. Randall, and G. Zandt, 1990: On the nonuniqueness of receiver function inversions. J. Geophys. Res., 95, 15303-15318, doi: 10.1029/ jb095ib10p15303. [Link]

Anczkiewicz, R., V. G. Viola, O. Müntener, M. F. Thirlwall, I. M. Villa, and N. Q. Quong, 2007: Structure and shearing conditions in the Day Nui Con Voi massif: Implications for the evolution of the Red River shear zone in northern Vietnam. Tectonics, 26, doi: 10.1029/2006tc001972. [Link]

Bai, L., T. Iidaka, H. Kawakatsu, Y. Morita, and N. Q. Dzung, 2009: Upper mantle anisotropy beneath Indochina block and adjacent regions from shear-wave splitting analysis of Vietnam broadband seismograph array data. Phys. Earth Planet. Inter., 176, 33-43, doi: 10.1016/j.pepi.2009.03.008. [Link]

Bai, L., X. Tian, and J. Ritsema, 2010: Crustal structure beneath the Indochina peninsula from teleseismic receiver functions. Geophys. Res. Lett., 37, doi: 10.1029/2010g1044874. [Link]

Balykin, P. A., G. V. Polyakov, A. E. Izokh, T. T. Hoa, N. T. Phuong, T. Q. Hung, and T. E. Petrova, 2010: Geochemistry and petrogenesis of Permian ultramaficmafic complexes of the Jinping-Song Da rift (southeastern Asia). Russ. Geol. Geophys., 51, 611-624, doi: 10.1016/j.rgg.2010.05.003. [Link]

Beaumont, C., R. A. Jamieson, M. H. Nguyen, and B. Lee, 2001: Himalayan tectonics explained by extrusion of a low-viscosity crustal channel coupled to focused surface denudation. Nature, 414, 738-742, doi: 10.1038/414738a. [Link]

Berteussen, K.-A., 1977: Moho depth determinations based on spectral-ratio analysis of NORSAR long-period $\mathrm{P}$ waves. Phys. Earth Planet. Inter., 15, 13-27, doi: 10.1016/0031-9201(77)90006-1. [Link]

Bui, C. Q., 1983: About the new results of the deep structural study of territory of Vietnam. Earth Sci., 5, 27-40.

Cao, D. T., 1985: The method interpret gravity data to research the Earth's crust of northern Vietnam. Proceedings of the Second Vietnam Scientific Conference on Geology, Vietnam Geological Survey, Hanoi, 27-40.

Cao, D. T. and V.-T. Dinh, 1999: Main crustal feature of the crust in Vietnam and adjacent area on the basic of gravity data. Proceedings of the fourth Vietnam National Conference on Marine Science and Technology, Hanoi, 854-863.

Cassidy, J. F., 1992: Numerical experiments in broadband receiver function analysis. Bull. Seismol. Soc. Am., 82, 1453-1474.

Chen, Y., F. Niu, R. Liu, Z. Huang, H. Tkalčić, L. Sun, and W. Chan, 2010: Crustal structure beneath China from receiver function analysis. J. Geophys. Res., 115, doi: 10.1029/2009jb006386. [Link]

Chung, S.-L., T.-Y. Lee, C.-H. Lo, P.-L. Wang, C.-Y. Chen, N. T. Yem, T. T. Hoa, and G. Wu, 1997: Intraplate extension prior to continental extrusion along the Ailao Shan-Red River shear zone. Geology, 25, 311-314, doi: 10.1130/0091-7613(1997)025<0311:IEPTCE >2. 3.CO;2. [Link]

Dang, T. H., 2003: Study on some characteristics of deep 
crustal structure and seismotectonic zonation in northern Vietnam. Ph.D. Thesis, Institute of Geophysics, VAST, $170 \mathrm{pp}$.

Deng, Y., J. Li, X. Song, H. Li, and T. Xu, 2019: The lithospheric-scale deformation in NE Tibet from joint inversion of receiver function and surface wave dispersion. Terr. Atmos. Ocean. Sci., 30, 127-137, doi: 10.3319/TAO .2019.01.18.03. [Link]

Dinh, V.-T., 2010: Study of the Earth Crustal structures of Northern Vietnam by using the deep seismic, magnetotelluric investigations and gravity data. Vietnam National Science Project: KC, Vietnam National Science Project: Outcome Report.

Dinh, V.-T., S. Harder, B.-S. Huang, V.-B. Trinh, V.-T. Doan, H.-P. Lai, A.-V. Tran, H. Q.-T. Nguyen, and V.D. Nguyen, 2018: An overview of northern Vietnam deep crustal structures from integrated geophysical observations. Terr. Atmos. Ocean. Sci., 29, 371-386, doi: 10.3319/TAO.2018.01.02.01. [Link]

Duong, N. A., T. Sagiya, F. Kimata, T. D. To, V. Q. Hai, D. C. Cong, N. X. Binh, and N. D. Xuyen, 2013: Contemporary horizontal crustal movement estimation for northwestern Vietnam inferred from repeated GPS measurements. Earth Planets Space, 65, 1399-1410, doi: 10.5047/eps.2013.09.010. [Link]

England, P. and G. Houseman, 1985: Role of lithospheric strength heterogeneities in the tectonics of Tibet and neighbouring regions. Nature, 315, 297-301, doi: 10.1038/315297a0. [Link]

England, P. and G. Houseman, 1986: Finite strain calculations of continental deformation: 2. Comparison with the India-Asia Collision Zone. J. Geophys. Res., 91, 3664-3676, doi: 10.1029/jb091ib03p03664. [Link]

Ford, H. A., M. D. Long, and E. A. Wirth, 2016: Midlithospheric discontinuities and complex anisotropic layering in the mantle lithosphere beneath the Wyoming and Superior Provinces. J. Geophys. Res., 121, 6675-6697, doi: 10.1002/2016JB012978. [Link]

Haskell, N. A., 1962: Crustal reflection of plane $P$ and $S V$ waves. J. Geophys. Res., 67, 4751-4768, doi: 10.1029/ JZ067i012p04751. [Link]

Hazarika, D., Arora, B.R., Bora, C., 2012: Crustal structure and deformation in the northeast India-Asia collision zone: Constraints from receiver function analysis. Geophys. J. Int., 188, 737-749, doi: 10.1111/j.1365246x.2011.05267.x. [Link]

Herrmann, R. B. and C. J. Ammon, 2003: Computer Programs in Seismology: Surface Waves, Receiver Functions and Crustal Structure, Version 3.20, Saint Louis University, Penn State University.

Hoa, T. T., A. E. Izokh, G. V. Polyakov, A. S. Borisenko, T. T. Anh, P. A. Balykin, N. T. Phuong, S. N. Rudnev, V. V. Van, and B. A. Nien, 2008: Permo-Triassic magma- tism and metallogeny of Northern Vietnam in relation to the Emeishan plume. Russ. Geol. Geophys., 49, 480491, doi: 10.1016/j.rgg.2008.06.005. [Link]

Huang, B.-S., T. S. Le, C.-C. Liu, D. V. Toan, W .-G. Huang, Y.-M. Wu, Y.-G. Chen, and W.-Y. Chang, 2009: Portable broadband seismic network in Vietnam for investigating tectonic deformation, the Earth's interior, and early-warning systems for earthquakes and tsunamis. J. Asian Earth Sci., 36, 110-118, doi: 10.1016/j. jseaes.2009.02.012. [Link]

Huang, H.-H., Z. J. Xu, Y.-M. Wu, X. Song, B.-S. Huang, and L. M. Nguyen, 2013: First local seismic tomography for Red River shear zone, northern Vietnam: Stepwise inversion employing crustal $\mathrm{P}$ and $\mathrm{P}_{\mathrm{n}}$ waves. Tectonophysics, 584, 230-239, doi: 10.1016/j.tecto.2012.03.030. [Link]

Huang, J., D. Zhao, and S. Zheng, 2002: Lithospheric structure and its relationship to seismic and volcanic activity in southwest China. J. Geophys. Res., 107, ESE 131-ESE 13-14, doi: 10.1029/2000JB000137. [Link]

Julià, J., 2007: Constraining velocity and density contrasts across the crust-mantle boundary with receiver function amplitudes. Geophys. J. Int., 171, 286-301, doi: 10.1111/j.1365-2966.2007.03502.x. [Link]

Julià, J., S. Jagadeesh, S. S. Rai, and T. J. Owens, 2009: Deep crustal structure of the Indian shield from joint inversion of $\mathrm{P}$ wave receiver functions and Rayleigh wave group velocities: Implications for Precambrian crustal evolution. J. Geophys. Res., 114, doi: 10.1029/2008jb006261. [Link]

Kennett, B. L. N., 1983: Seismic Wave Propagation in Stratified Media, Cambridge University Press, Cambridge, England, 242 pp.

Lan, C.-Y., S.-L. Chung, J. J.-S. Shen, C.-H. Lo, P.-L. Wang, T. T. Hoa, H. H. Thanh, and S. A. Mertzman, 2000: Geochemical and Sr-Nd isotopic characteristics of granitic rocks from northern Vietnam. J. Asian Earth Sci., 18, 267-280, doi: 10.1016/s1367-9120(99)000632. [Link]

Lan, C.-Y., S.-L. Chung, C.-H. Lo, T.-Y. Lee, P.-L. Wang, H. Li, and D. Van Toan, 2001: First evidence for Archean continental crust in northern Vietnam and its implications for crustal and tectonic evolution in Southeast Asia. Geology, 29, 219-222, doi: 10.1130/0091-7613(2001)029<0219:FEFACC >2.0 . $\mathrm{CO} ; 2$. [Link]

Langston, C. A., 1979: Structure under Mount Rainier, Washington, inferred from teleseismic body waves. J. Geophys. Res., 84, 4749-4762, doi: 10.1029/ JB084iB09p04749. [Link]

Le, D. B., 1985: Structure of Vietnam and stages of its formation - on the background of SE Asia. Ph.D. Thesis, Hanoi National Library, Hanoi, 36 pp. 
Le, H. M., T. S. Vo, C. T. Nguyen, T. V. Nguyen, D. X. Nguyen, G. Marquis, and V. T. Tran, 2008: Two dimensional electrical structure of the Son La fault zone on the results of magnetotelluric sounding. Earth Sci. Hanoi, 30, 491-502.

Le, H. M., V. N. Pham, D. Boyer, N. T. Nguyen, T. T. Le, V. Q. Nguyen, and G. Marquis, 2009: Investigation on the deep geoelectric structure of the Lai Chau-Dien Bien fault zone by magnetotelluric sounding. J. Geol. Hanoi, A311, 11-21.

Le, H. M., R. Masson, A. Bourdillon, R. Fleury, J.-C. Hu, V. T. Hung, L. T. Thanh, N. C. Thang, and N. H. Thanh, 2014: Recent crustal motion in Vietnam and in the Southeast Asia region by continuous GPS data. Vietnam Journal of Earth Sciences, 36, 1-13, doi: 10.15625/0866-7187/36/1/4132. [Link]

Le, T. S., 2008: Study on seismic wave attenuation and velocity model in order to improve the reliability of the forecast of geological disasters in North Vietnam. Institute of Geophysics, VAST. (in Vietnamese)

Lebedev, S. and G. Nolet, 2003: Upper mantle beneath Southeast Asia from $S$ velocity tomography. J. Geophys. Res., 108, doi: 10.1029/2000jb000073. [Link]

Legendre, C. P., L. Zhao, W.-G. Huang, and B.-S. Huang, 2015: Anisotropic Rayleigh-wave phase velocities beneath northern Vietnam. Earth Planets Space, 67, doi: 10.1186/s40623-015-0193-3. [Link]

Lei, J., D. Zhao, and Y. Su, 2009: Insight into the origin of the Tengchong intraplate volcano and seismotectonics in southwest China from local and teleseismic data. J. Geophys. Res., 114, B05302, doi: 10.1029/2008jb005881. [Link]

Leloup, P. H., R. Lacassin, P. Tapponnier, U. Schärer, D. Zhong, X. Liu, L. Zhang, S. Ji, and P. T. Trinh, 1995: The Ailao Shan-Red River shear zone (Yunnan, China), Tertiary transform boundary of Indochina. Tectonophysics, 251, 3-84, doi: 10.1016/0040-1951(95)000704. [Link]

Leloup, P. H., N. Arnaud, R. Lacassin, J. R. Kienast, T. M. Harrison, T. T. P. Trong, A. Replumaz, and P. Tapponnier, 2001: New constraints on the structure, thermochronology, and timing of the Ailao Shan-Red River shear zone, SE Asia. J. Geophys. Res., 106, 6683-6732, doi: 10.1029/2000jb900322. [Link]

Levin, V. and J. Park, 1997: P-SH conversions in a flat-layered medium with anisotropy of arbitrary orientation. Geophys. J. Int., 131, 253-266, doi: 10.1111/j.1365246x.1997.tb01220.x. [Link]

Li, C. and R. D. van der Hilst, 2010: Structure of the upper mantle and transition zone beneath Southeast Asia from traveltime tomography. J. Geophys. Res., 115, doi: 10.1029/2009jb006882. [Link]

Li, Y., Q. Wu, R. Zhang, X. Tian, and R. Zeng, 2008: The crust and upper mantle structure beneath Yunnan from joint inversion of receiver functions and Rayleigh wave dispersion data. Phys. Earth Planet. Inter., 170, 134-146, doi: 10.1016/j.pepi.2008.08.006. [Link]

Ligorría, J. P., 2000: An Investigation of the Mantle-Crust Transition Beneath North America \& Poisson's Ratio of the North American Crust, Graduate School, Saint Louis University, USA, 261 pp.

Ligorría, J. P. and C. J. Ammon, 1999: Iterative deconvolution and receiver-function estimation. Bull. Seismol. Soc. Am., 89, 1395-1400.

Liong Tin, H. and O. K. Litvinenko, 1986: The structure of the Earth's crust of the Hanoi tectonic trough according to geophysical data and the problem of its riftogenesis. J. Geodyn., 5, 179-203, doi: 10.1016/02643707(86)90005-0. [Link]

Liu, Q. Y., R. D. van der Hilst, Y. Li, H. J. Yao, J. H. Chen, B. Guo, S. H. Qi, J. Wang, H. Huang, and S. C. Li, 2014: Eastward expansion of the Tibetan Plateau by crustal flow and strain partitioning across faults. Nat. Geosci., 7, 361-365, doi: 10.1038/ngeo2130. [Link]

Molnar, P. and K. E. Dayem, 2010: Major intracontinental strike-slip faults and contrasts in lithospheric strength. Geosphere, 6, 444-467, doi: 10.1130/ges00519.1. [Link]

Molnar, P. and P. Tapponnier, 1975: Cenozoic Tectonics of Asia: Effects of a Continental Collision. Science, 189, 419-426, doi: 10.1126/science.189.4201.419. [Link]

Nguyen, D. X. and T. S. Le, 2005: Seismic hazard assessment for Vietnam Territory. Proceeding of the 4th Conference of Vietnamese Association of Geophysics, Publishing House of Science and Technology, Hanoi, Vietnam, 281-304.

Nguyen, V.-D., B.-S. Huang, T.-S. Le, V.-T. Dinh, L. Zhu, and K.-L. Wen, 2013b: Constraints on the crustal structure of northern Vietnam based on analysis of teleseismic converted waves. Tectonophysics, 601, 87-97, doi: 10.1016/j.tecto.2013.04.031. [Link]

Owens, T. J. and R. S. Crosson, 1988: Shallow structure effects on broadband teleseismic $P$ waveforms. Bull. Seismol. Soc. Am., 78, 96-108.

Owens, T. J., G. Zandt, and S. R. Taylor, 1984: Seismic evidence for an ancient rift beneath the Cumberland Plateau, Tennessee: A detailed analysis of broadband teleseismic $P$ waveforms. J. Geophys. Res., 89, 77837795, doi: 10.1029/jb089ib09p07783. [Link]

Ozacar, A. A. and G. Zandt, 2004: Crustal seismic anisotropy in central Tibet: Implications for deformational style and flow in the crust. Geophys. Res. Lett., 31, doi: 10.1029/2004g1021096. [Link]

Qiao, L., H. Yao, Y.-C. Lai, B.-S. Huang, and P. Zhang, 2018: Crustal structure of southwest China and northern Vietnam from ambient noise tomography: 
Implication for the large-scale material transport model in SE Tibet. Tectonics, 37, 1492-1506, doi: 10.1029/2018TC004957. [Link]

Randall, G. E., 1989: Efficient calculation of differential seismograms for lithospheric receiver functions. Geophys. J. Int., 99, 469-481, doi: 10.1111/j.1365246x.1989.tb02033.x. [Link]

Reading, A. M., H. Tkalčić, B. L. Kennett, S. P. Johnson, and S. Sheppard, 2012: Seismic structure of the crust and uppermost mantle of the Capricorn and Paterson Orogens and adjacent cratons, Western Australia, from passive seismic transects. Precambrian Res., 196197, 295-308, doi: 10.1016/j.precamres.2011.07.001. [Link]

Roger, F., P. H. Leloup, M. Jolivet, R. Lacassin, P. T. Trinh, M. Brunel, and D. Seward, 2000: Long and complex thermal history of the Song Chay metamorphic dome (Northern Vietnam) by multi-system geochronology. Tectonophysics, 321, 449-466, doi: 10.1016/s00401951(00)00085-8. [Link]

Royden, L., 1996: Coupling and decoupling of crust and mantle in convergent orogens: Implications for strain partitioning in the crust. J. Geophys. Res., 101, 1767917705, doi: 10.1029/96jb00951. [Link]

Royden, L. H., B. C. Burchfiel, R. W. King, E. Wang, Z. Chen, F. Shen, and Y. Liu, 1997: Surface deformation and lower crustal flow in eastern Tibet. Science, 276, 788-790, doi: 10.1126/science.276.5313.788. [Link]

Royden, L. H., B. C. Burchfiel, and R. D. van der Hilst, 2008: The geological evolution of the Tibetan Plateau. Science, 321, 1054-1058, doi: 10.1126/science.1155371. [Link]

Searle, M. P., 2006: Role of the Red River Shear zone, Yunnan and Vietnam, in the continental extrusion of SE Asia.J.Geol.Soc., 163, 1025-1036, doi: 10.1144/001676492005-144. [Link]

Shearer, P. M., 1999: Introduction to Seismology, Cambridge University Press, Cambridge, Cambridge, New York, Melbourne, $272 \mathrm{pp}$.

Shen, Z.-K., J. Lü, M. Wang, and R. Bürgmann, 2005: Contemporary crustal deformation around the southeast borderland of the Tibetan Plateau. J. Geophys. Res., 110, B11409, doi: 10.1029/2004jb003421. [Link]

Sun, Y., S. Dong, H. Zhang, H. Li, and Y. Shi, 2013: 3D thermal structure of the continental lithosphere beneath China and adjacent regions. J. Asian Earth Sci., 62, 697-704, doi: 10.1016/j.jseaes.2012.11.020. [Link]

Tapponnier, P., G. Peltzer, A. Y. Le Dain, R. Armijo, and P. Cobbold, 1982: Propagating extrusion tectonics in Asia: New insights from simple experiments with plasticine. Geology, 10, 611-616, doi:
10.1130/0091-7613(1982)10<611:PETIAN>2.0. $\mathrm{CO} ; 2$. [Link]

Tapponnier, P., R. Lacassin, P. H. Leloup, U. Schärer, D. Zhong, H. Wu, X. Liu, S. Ji, L. Zhang, and J. Zhong, 1990: The Ailao Shan/Red River metamorphic belt: Tertiary left-lateral shear between Indochina and South China. Nature, 343, 431-437, doi: 10.1038/343431 a0. [Link]

Tapponnier, P., Z. Xu, F. Roger, B. Meyer, N. Arnaud, G. Wittlinger, and J. Yang, 2001: Oblique Stepwise Rise and Growth of the Tibet Plateau. Science, 294, 16711677, doi: 10.1126/science.105978. [Link]

Tkalčić, H., Y. Chen, R. Liu, H. Zhibin, L. Sun, and W. Chan, 2011: Multistep modelling of teleseismic receiver functions combined with constraints from seismic tomography: Crustal structure beneath southeast China. Geophys. J. Int., 187, 303-326, doi: 10.1111/j.1365246x.2011.05132.x. [Link]

Trần, Đ. T., T. Y. Nguyễn, C. C. Dương, Q. H. Vy, W. Zuchiewicz, Q. C. Nguyễn, and V. N. Nguyễn, 2013: Recent crustal movements of northern Vietnam from GPS data. J. Geodyn., 69, 5-10, doi: 10.1016/j. jog.2012.02.009. [Link]

Trinh, P. T., N. V. Liem, N. V. Huong, H. Q. Vinh, B. V. Thom, B. T. Thao, M. T. Tan, and N. Hoang, 2012: Late Quaternary tectonics and seismotectonics along the Red River fault zone, North Vietnam. Earth-Sci.Rev., 114, 224-235, doi: 10.1016/j.earscirev.2012.06.008. [Link]

Vinnik, L. P., 1977: Detection of waves converted from P to $\mathrm{SV}$ in the mantle. Phys. Earth Planet. Inter., 15, 39-45, doi: 10.1016/0031-9201(77)90008-5. [Link]

Wang, P.-L., C.-H. Lo, S.-L. Chung, T.-Y. Lee, C.-Y. Lan, and T. Van Thang, 2000: Onset timing of left-lateral movement along the Ailao Shan-Red River Shear Zone: ${ }^{40} \mathrm{Ar} /{ }^{39} \mathrm{Ar}$ dating constraint from the Nam Dinh Area, northeastern Vietnam. J. Asian Earth Sci., 18, 281-292, doi: 10.1016/s1367-9120(99)00064-4. [Link]

Wirth, E. A. and M. D. Long, 2012: Multiple layers of seismic anisotropy and a low-velocity region in the mantle wedge beneath Japan: Evidence from teleseismic receiver functions. Geochem. Geophys. Geosyst., 13, Q08005, doi: 10.1029/2012GC004180. [Link]

Xu, L., S. Rondenay, and R. D. van der Hilst, 2007: Structure of the crust beneath the southeastern Tibetan Plateau from teleseismic receiver functions. Phys. Earth Planet. Inter., 165, 176-193, doi: 10.1016/j. pepi.2007.09.002. [Link]

Zhu, L. and H. Kanamori, 2000: Moho depth variation in southern California from teleseismic receiver functions. J. Geophys. Res., 105, 2969-2980, doi: 10.1029/1999JB900322. [Link] 